\title{
TEORIA DO EMPODERAMENTO COMO MEIO DE SUPERAÇÃO ÀS BARREIRAS INTERSECCIONAIS ENTRE GÊNERO, RAÇA E CLASSE
}

\author{
Carla Bertocini $*^{1}$ \\ Tayana R. M. Caldonazzo $* *^{2}$ \\ Fernanda C. A. Mattos $* * *^{3}$
}

\section{RESUMO}

O presente trabalho, vinculado à área do Direito - subárea Direito Constitucional - e gênero, aborda vulnerabilidades que atingem mulheres negras. Dados apontam que são alvos de maior vitimização em relação à violência, além de se encontrarem em situação desigual em diversas áreas. Diante disso, problematiza-se: de que maneira o empoderamento contribui para a efetivação do direito fundamental a igualdade dessas mulheres? Parte-se da hipótese - que se concluiu - de que o empoderamento é uma ferramenta de enfrentamento às estruturas sociais opressoras, e contribui porque se relaciona à conscientização sobre as vulnerabilidades, permitindo a criação de estratégias de enfrentamento.

Palavras-chave: Racismo; Movimento negro; Feminismo negro; Interseccionalidade; Estruturas sociais.

\section{EMPOWERMENT THEORY AS A MEANS OF OVERCOMING INTERSECTIONAL BARRIERS BETWEEN GENDER, RACE AND CLASS}

\begin{abstract}
This reserach, related to the area of Law - subarea Constitutional Law - and gender, addresses vulnerabilities that affect black women. They are targets of greater victimization in relation to violence, besides being in unequal situation in several areas. Than, it is problematized: in which way the empowerment contributes for the effectiveness of the fundamental right to equality of these women? The hypothesis - which has been concluded - is that empowerment
\end{abstract}

\footnotetext{
1 * Doutora em Direito pela Pontifícia Universidade Católica de São Paulo (subárea de concentração Direito Civil) - PUC (2011). Bacharel em Direito pela Instituição Toledo de Ensino - ITE (1992). Mestre em Direito pela Instituição Toledo de Ensino - ITE (2001). Atualmente é professora adjunta do curso de Pós-graduação stricto sensu (Mestrado/Doutorado) e do curso de graduação da Faculdade de Direito do Centro de Ciências Sociais Aplicadas da Universidade Estadual do Norte do Paraná - UENP, Campus de Jacarezinho e professora de Direito Civil (Direito de Família e Sucessões) das Faculdades Integradas de Ourinhos (UNI/FIO), além de ser advogada. Atua em pesquisas relacionadas ao Direito, com ênfase em Direito Civil. Currículo lattes: http://lattes.cnpq.br/8287398590266450.E-mail: carla.bertoncini@uenp.edu.br.

2 ** Mestranda em Ciência Jurídica pela Universidade Estadual do Norte do Paraná - UENP. Área de Concentração: Teorias da Justiça: Justiça e Exclusão. Linha de Pesquisa: Função Política do Direito. Bolsista pela Coordenação de Aperfeiçoamento de Pessoal de Nível Superior (CAPES). Graduada em Direito pela Universidade Estadual do Norte do Paraná - UENP. Participante do Grupo de Pesquisa Intervenção do Estado na Vida das Pessoas do diretório CNPq. Pesquisa sobre Direito e Gênero, com ênfase em grupos reflexivos para autores de violência doméstica contra a mulher e masculinidades. Currículo lattes: http://lattes.cnpq.br/9759779920993502. E-mail: tayana.rmc@gmail.com.

3 *** Mestranda em Ciência Jurídica pela Universidade Estadual do Norte do Paraná - UENP. Área de Concentração: Teorias da Justiça: Justiça e Exclusão. Linha de pesquisa: Estado e Responsabilidade: questões críticas. Bolsista pela Coordenação de Aperfeiçoamento de Pessoal de Nível Superior (CAPES). Graduada em Direito pela Universidade Tiradentes - UNIT/SE. Participante do Grupo de pesquisa Intervenção do Estado na vida das pessoas do diretório CNPq. Atua em pesquisas relacionadas a Direitos Humanos, Direito Penal, Filosofia Jurídica, Sociologia Jurídica e Direito Constitucional, com ênfase na relação entre Gênero e Direito. Currículo lattes: http://lattes.cnpq.br/3266505536822300. E-mail: mattos.fernandac@gmail.com.
} 
is a tool for confronting oppressive social structures, and contributes because it is related to the awareness of vulnerabilities, allowing the creation of confrontation strategies.

Keywords: Racism; Black movement; Black feminism; Intersectionality; Social Structures.

\section{INTRODUÇÃO}

Esta pesquisa vincula-se à área do Direito - subárea Direito Constitucional - e gênero, enfatizando vulnerabilidades que atingem mulheres negras em razão da intersecção entre gênero, raça e classe. Justifica-se o estudo a partir de dados que demonstram o racismo contra mulheres no Brasil, a exemplo de taxas de violência - inclusive doméstica - que as atingem, além de desigualdades nas searas laboral, educacional, tentativa de controle de natalidade, dentre outras afins, que demonstram a constante violação de seus direitos fundamentais, especialmente o da igualdade, indicando-se também a necessidade de aprofundamento na temática.

Diante disso, a presente pesquisa se propõe a responder: de que maneira o empoderamento feminino contribui para a efetivação do direito fundamental a igualdade das mulheres negras? Para responder ao questionamento, partiu-se da hipótese de que o empoderamento - entendido como uma ferramenta voltada à transformação de estruturas sociais opressoras - tende a contribuir na medida em que remete a um processo de conscientização a nível individual e coletivo sobre as vulnerabilidades, permitindo a criação de estratégias de enfrentamento, sendo imprescindível também, nesse caminho, a transformação de estruturas de poder, conforme lições de Berth (2019), Batliwala (1994), León (2001) e Romano (2002).

Para tanto, na primeira seção descreveram-se parte das desigualdades que atingem mulheres negras, especialmente as relacionadas à violência de gênero, desigualdade em diversos setores e contribuições sociais e institucionais para a manutenção desse cenário. Diante disso, verificou-se a importância do movimento negro e do feminismo negro para explicitar as demandas dessas mulheres, trazendo voz.

Essa realidade indicou um aprofundamento necessário na temática, razão pela qual se estudou a vertente interseccional do feminismo em um segundo momento. Esse viés permite um entendimento mais completo sobre as relações entre gênero, raça, classe, e suas consequências na vida das mulheres. Por fim, verificou-se de que maneira a teoria do empoderamento pode contribuir para a efetivação dos direitos fundamentais das mulheres negras, especialmente o da igualdade. 
O referencial teórico alinhou-se à vertente feminista interseccional, especialmente a partir de autoras como Crenshaw (2002), Oliviera (2016) e Schwarcz (2019). Em relação às lições sobre feminismo negro, receberam ênfase autoras como Bertúlio (1989), Almeida (2019), Carneiro (2003), Akotirene (2019) e Ribeiro (2019). Quanto à Teoria do Empoderamento, Berth (2019), Batliwala (1994), León (2001), Romano (2002) e Sardenberg (2012) foram imprescindíveis para o desenvolvimento da pesquisa.

Para tanto, utilizou-se o método de abordagem dedutivo, partindo-se da premissa de que a vulnerabilidade das mulheres negras demandam aprofundamento, e de que o feminismo negro e análise intersecional contribuem para a explicitação de demandas e um entendimento mais completo de suas realidades, chegando-se a conclusão de que o empoderamento é um dos instrumentos que tendem a ser eficazes na efetivação dos direitos fundamentais das mulheres negras. Além disso, realizam-se pesquisas bibliográficas em teses, dissertações, periódicos e reportagens.

\section{RACISMO CONTRA MULHERES NO BRASIL E A IMPORTÂNCIA DO FEMINISMO NEGRO}

Recebem enfoque, neste trabalho, as vulnerabilidades que atingem minorias políticas ${ }^{4}$, fazendo-se um recorte para mulheres negras. De início, cumpre destacar a restrição do olhar crítico posicional ${ }^{5}$, haja vista o lugar de fala ${ }^{6}$ (RIBEIRO, 2017) ocupado pelas autoras que possuem diversos privilégios, dentre eles, a branquitude. No entanto, essa demarcação, enquanto guia ético-político do trabalho, não constitui barreira invencível quanto

\footnotetext{
${ }^{4}$ Para Marcia Tiburi (2018, p. 951), deve-se falar em "minorias políticas", pois somente o uso do termo "minoria" não recebe o sentido devido. Em sua visão, "não poderia deixar de ser assim, uma vez que a participação política implica a entrada do corpo marcado no lugar que o poder reservou para si contra os corpos, aquele lugar onde o poder se exerce para dominar o outro, para subjugar, para submeter, transformando cada um em objeto: o trabalhador no capitalismo, a mulher no patriarcado, o negro na raça [...]. A consciência disso levou a um ato de contramarcação politicamente produtivo: hoje as mulheres se autoafirmam como categoria política, bem como as mulheres negras [...], sempre tendo em vista a reivindicação de direitos. Só se entra na esfera política quando se quebra a blindagem do poder" [...] (p. 951).

${ }_{5}^{5}$ Lima (2018) cita o termo com base em bell hooks.

${ }^{6}$ Patrícia Hills Collins é referência no estudo do feminist stand point (RIBEIRO, 2017). Pensando-se na correlação entre essa teoria e o lugar de fala, a hipótese de Ribeiro $(2017$, p. 34) "é que a partir da teoria do ponto de vista feminista, é possível falar de lugar de fala". A autora explicita que determinados grupos, que são socialmente posicionados de forma hierarquicamente inferior, possuem suas produções e vozes negligenciadas, neutralizadas, silenciadas (RIBEIRO, 2017). "Essas experiências comuns resultantes do lugar social que ocupam impedem que a população negra acesse a certos espaços. É aí que entendemos que é possível falar de lugar de fala a partir do feminist standpoint: não poder acessar certos espaços, acarreta em não se ter produções e epistemologias desses grupos nesses espaços; não poder estar de forma justa nas universidades, meios de comunicação, política institucional, por exemplo, impossibilita que as vozes dos indivíduos desses grupos sejam catalogadas, ouvidas [...]. O falar não se restringe ao ato de emitir palavras, mas de poder existir. Pensamos lugar de fala como refutar a historiografia tradicional e a hierarquização de saberes consequente da hierarquia social" (p. 35-36).
}

CONPEDI LAW REVIEW | EVENTO VIRTUAL | v. 6 | n. 1 | p. 19 - 35 | JAN - DEZ | 2020 
à criação de ferramentas (LIMA, 2018) que enfrentem as consequências de uma sociedade racista.

Para exemplificar as incidências do racismo contra mulheres no Brasil, inicia-se problematizando a violência traduzida em dados: o Atlas da Violência (2019), organizado pelo Instituto de Pesquisa Econômica Aplicada e Fórum Brasileiro de Segurança Pública, aponta a desigualdade racial tendo em vista dados de homicídios de mulheres. Ao tempo em que taxa de homicídios de mulheres não negras aumentou 4,5\% entre 2007 e 2017, a porcentagem de crescimento para mulheres negras foi de $29,9 \%$, no mesmo período. Alertouse também que 66\% de todas as mulheres assassinadas no Brasil em 2017 são negras, e conclui serem esses resultados decorrentes dos problemas que este país possui em universalizar suas políticas públicas.

No que se refere à violência doméstica, observam-se dados que indicam vitimizações majoritárias contra mulheres negras. O Mapa da Violência 2015, que estuda os homicídios de mulheres no Brasil, afirma que os números homicídios de mulheres brancas, entre 2003 e 2013, apresentaram uma diminuição de 9,8\%. No entanto, quanto às vítimas negras houve um aumento de 54,2\% no mesmo intervalo de tempo. Movimento similar ocorreu a partir da vigência da Lei Maria da Penha: ao passo que o número de vítimas brancas diminuiu 2,1\%, o de mulheres negras aumentou 35,0\%. Pensando-se em taxas, pode-se afirmar que entre 2003 e 2013, a taxa ${ }^{7}$ de homicídios de mulheres brancas apresentou queda de $11,9 \%$, enquanto que em relação às mulheres negras, essa taxa cresceu 19,5\% (WAISELFISZ, 2015, p. 31).

Oliveira (2016, p. 116), analisando a efetividade da Lei Maria da Penha, aponta uma responsabilidade estatal diante de denúncias que indicam seu descumprimento. Tendo como base o Mapa da Violência de 2015, considera que a violência recai de forma mais expressiva em mulheres negras, além de concluir pela necessidade de políticas públicas que se refiram à prevenção e enfrentamento da violência. "Uma análise possível é que as mulheres brancas têm sido mais beneficiadas pelos mecanismos de proteção da $\mathrm{LMP}^{8}$, enquanto que as mulheres negras não têm usufruído integral e efetivamente desses instrumentos” (p. 117).

\footnotetext{
${ }^{7}$ Segundo Waiselfisz (2015, p. 32), "essa distância relativa, entre as taxas de vítimas brancas e negras, é o que denominamos de índice de vitimização negra, que nada mais é do que a diferença entre as taxas de homicídio de mulheres de ambos os grupos. Vemos que o índice de vitimização negra, em 2003, era de 22,9\%, isso é, proporcionalmente, morriam assassinadas $22,9 \%$ mais negras do que brancas. $\mathrm{O}$ índice foi crescendo lentamente, ao longo dos anos, para, em 2013, chegar a 66,7\%. Esse largo diferencial nas taxas de homicídios, pela cor das vítimas, faz com que os índices de vitimização de mulheres negras [...] apresentem, de 2003 a 2012, uma escala íngreme, sendo 2013 o único ano em que o índice cai: de 77,1\% para 66,7\%. Será esta uma tendência? Devemos ter esperanças, mas ainda é cedo para a queda ser considerada não um acidente de percurso, pois para configurar uma tendência seriam necessários três anos consecutivos de quedas".

${ }^{8}$ Referência à Lei Maria da Penha (OLIVEIRA, 2016).
}

CONPEDI LAW REVIEW | EVENTO VIRTUAL | v. 6 | n. 1 | p. 19 - 35 | JAN - DEZ | 2020 
Além disso, outras vulnerabilidades atingem majoritariamente mulheres negras. Bertúlio (1989) aduz que crescem as demandas sociais sobre controle populacional de camadas mais pobres, por meio da contenção de natalidade ${ }^{9}$, que normalmente recai sobre pessoas negras. Nesse sentido: “[...] Negras são, também grande parte das crianças impedidas de nascer pelo controle de natalidade [...]” (p. XIX-XX).

Depreende-se, a partir de Almeida (2018) que outro ponto se relaciona à desigualdade laboral e educacional, ou sobre a naturalização da ausência de pessoas negras nesses setores. Almeida (2018, p. 48) problematiza a seguinte frase, entendida como uma meia-verdade: "pessoas negras, por fatores históricos, têm menos acesso à educação e, por isso, estão alocadas em trabalhos menos qualificados e, consequentemente, mal remunerados". Considera que embora os negros possuam menores índices de escolaridade, há omissão explicativa quanto aos porquês de essas pessoas terem acesso restrito à seara educacional (ALMEIDA, 2018).

Além disso, segundo o autor, em que pese teorias racistas já estejam desmoralizadas, ainda se ouve que os negros não seriam aptos a ocupar determinadas posições. Diante disso, indaga sobre a forma como essas ideias são transmitidas, contribuindo com uma desigualdade racial. Questiona-se, também, sobre a naturalização da falta de pessoas negras em determinados espaços, como escritórios de advocacia, cursos de medicina e bancadas jornalísticas (ALMEIDA, 2018), concluindo que:

Todas essas questões só podem ser respondidas se compreendermos que o racismo, enquanto processo político e histórico, é também um processo de constituição de subjetividades, de indivíduos cuja consciência e os afetos estão de algum modo conectados com as práticas sociais. [...] O racismo só consegue se perpetuar se for capaz de: 1. produzir um sistema de ideias que forneça uma explicação "racional" para a desigualdade racial; 2. Constituir sujeitos cujos sentimentos não sejam profundamente abalados diante da discriminação e da violência racial e que considerem "normal" e "natural" que no mundo haja "brancos" e "não-brancos" (ALMEIDA, 2018, p. 49).

Especificamente quanto ao trabalho doméstico realizado no Brasil, a maioria é realizada por mulheres negras (REDAÇÃO, 2015). Nesse sentido, a obra "Eu, empregada doméstica", cuja autoria pertence à Preta Rara, retrata uma série de episódios de racismo, assédios e violações a direitos humanos que recaem sobre essas trabalhadoras (SUDRÉ,

\footnotetext{
9 Angela Davis, na obra "Mulheres, raça e classe", traz informações sobre a ocorrência de esterilização compulsória correlacionada ao racismo nos Estados Unidos. Como exemplo, mencionou que a partir de 1933, foram realizadas 7.686 esterilizações, justificadas com o objetivo de impedir a reprodução de "pessoas com deficiência mental", e aproximadamente 5.000 delas realizaram-se em pessoas negras (HAROLD, apud DAVIS, 2016). A prática da esterilização compulsória também atingiu indígenas (ARLENE, apud DAVIS, 2016).
}

CONPEDI LAW REVIEW | EVENTO VIRTUAL | v. 6 | n. 1 | p. 19 - 35 | JAN - DEZ | 2020 
2019). Akotinene (2019) destaca que as mulheres negras são vítimas de racismo e sexismo por parte "das instituições públicas e privadas por lhes negarem primeiro trabalho e, depois, o direito humano de serem reclamantes das discriminações sofridas” (p. 541-555).

O Direito tem sua dinâmica interseccional, misoginias e racismos institucionais e dá conta dos mesmos recursos administrativos responsáveis por obstruir às mulheres negras o direito de registrarem queixas, levando em conta discursos prévios sobre mulheres fáceis, raivosas, perigosas, sexualmente disponíveis (AKOTIRENE, 2019, p. 658).

Diante desses dados, verifica-se a importância do feminismo negro que, para Oliveira (2016, p. 108), ao lado do movimento negro, coloca "os questionamentos necessários para que estes de fato se construam considerando a realidade social de todas as mulheres". Para Ribeiro (2018, p. 1517), em uma sociedade com marcas da escravidão, patriarcado e divisão de classes, o feminismo negro traz uma enorme contribuição para que se pense em um "novo marco civilizatório" $" 10$.

Sueli Carneiro, em artigo intitulado "Mulheres em movimento", ensina de que forma essa vertente contribuiu para realçar as demandas das mulheres que representa. Faz uso da expressão "enegrecendo o feminismo" para destacar o caminho percorrido por mulheres negras dentro do feminismo. Relata também que uma versão "clássica feminista" é inspirada em pessoas brancas e ocidentais, e ao mesmo tempo, demonstra que teoria e prática política até então utilizadas são insuficientes para abarcar as diferentes formas de expressão femininas numa sociedade marcada pela multirracialidade e diferentes culturas. Diante disso, pensou-se em uma política que enfrentasse desigualdades de gênero e também as existentes “intragênero" (CARNEIRO, 2003, p. 118).

Nesse contexto, "afirmamos e visibilizamos uma perspectiva feminista negra que emerge da condição específica do ser mulher, negra e, em geral, pobre, delineamos, por fim, o papel que essa perspectiva tem na luta anti-racista (sic) no Brasil” (CARNEIRO, 2003, p. 118). Após demonstrar contribuições do movimento em diversas áreas, a autora sintetiza algumas ações políticas de destaque provenientes dessa luta (CARNEIRO, 2003, p. 129):

O reconhecimento da falácia da visão universalizante de mulher; o reconhecimento das diferenças intragênero; o reconhecimento do racismo e da discriminação racial como fatores de produção e reprodução das desigualdades sociais experimentadas pelas mulheres no Brasil; o reconhecimento dos privilégios que essa ideologia produz para as mulheres do grupo racial hegemônico; o reconhecimento da

\footnotetext{
${ }^{10}$ Ao final do capítulo, a autora ressalva que o texto foi publicado, de início, na Revista Internacional de Direitos Humanos no ano de 2016 (RIBEIRO, 2018). 
necessidade de políticas específicas para as mulheres negras para a equalização das oportunidades sociais; o reconhecimento da dimensão racial que a pobreza tem no Brasil e, consequentemente, a necessidade do corte racial na problemática da feminilização da pobreza; o reconhecimento da violência simbólica e a opressão que a brancura, como padrão estético privilegiado e hegemônico, exerce sobre as mulheres não-brancas.

Apesar dos avanços, restam inúmeros desafios. Parcela das feministas brancas ainda precisa compreender que embora as mulheres se unam em torno das questões de gênero, há certos aspectos que irão distanciá-las. Deve-se reconhecer a diversidade de mulheres, rompendo-se com um olhar de universalidade (RIBEIRO, 2018) ${ }^{11}$. Além disso, segundo Berth (2019), as lições de Crenshaw, Lorde, Carneiro e demais autoras, permitem compreender que não se deve criar uma hierarquia de opressões, e sim considerá-las sob uma perspectiva interseccional. De modo que, as opressões se relacionam e se somam, refletindo-se de diferentes formas sobre os indivíduos.

Akortinere (2019), por sua vez, entende que o feminismo branco, movimentos antirracistas e afins, têm obstáculos metodológicos para pensar em identidades intersecionais. O cenário brasileiro é marcado por algumas especificidades:

\begin{abstract}
No campo jurídico, podemos identificar a exclusão racial por critério de gênero promovida pelo universalismo das políticas públicas relacionadas, o fato de mulheres e meninas negras estarem situadas em pelo menos dois grupos subordinados que, frequentemente, perseguem agendas contraditórias, dando impressão de que todas as violências policiais dilatadas para o sistema penal são contra homens negros. Todas as violências domésticas dilatadas para o encarceramento feminino ou feminicídios são impostas às mulheres brancas. [...] $\mathrm{O}$ padrão colonial ora elege as mulheres negras como dirigentes do tráfico de drogas, ora homicidas de companheiros violentos, quando não, pactuam com as coações impostas por filhos e maridos encarcerados para que transportem drogas até o sistema prisional, numa faceta hedionda punitivista das mulheres negras (AKOTIRENE, 2019, p. 524).
\end{abstract}

Assim, nota-se que apesar de as mulheres possuírem vulnerabilidades decorrentes, dentre outras razões, da desigualdade de gênero, há especificidades que atingem mulheres negras, não sendo possível universalizar o sujeito "mulher" ${ }^{\prime 2}$. Insere-se, diante disso, o destaque do movimento de mulheres negras e o feminismo negro, que contribuem para que suas demandas sejam expostas.

\title{
3 A INTERSECCIONALIDADE ENTRE GÊNERO, RAÇA E CLASSE
}

\footnotetext{
${ }^{11}$ Segundo a autora, o capítulo já foi publicado no blog CartaCapital em 2015 (RIBEIRO, 2018).

${ }^{12}$ Para Ribeiro (2018, p. 648), "é necessário entender de uma vez por todas que existem várias mulheres contidas nesse ser mulher e romper com a tentação da universalidade, que só exclui".
} 
Em seção anterior, investigaram-se problemas sociais graves que atingem mulheres negras. A partir disso, é possível constatar a demanda de um aprofundamento na temática. Indica-se, assim, de que forma uma visão interseccional entre gênero, classe e raça permite uma melhor compreensão dessa realidade.

Oliveira (2016) afirma que a politização do conceito de raça é importante para que aja como instrumento de luta contra o racismo. Nesse movimento, "deve-se também perceber a importância da interseção da raça com o gênero e atentar para as especificidades do racismo que atinge as mulheres negras" (p. 109).

Nesse sentido, Biroli e Miguel (2015) apontam a correlação entre capitalismo e dominação de gênero. Abordagens decorrentes dessa junção “expõem a inclusão desigual das mulheres nas relações de trabalho no capitalismo, jogando luz sobre a vida doméstica e sobre as conexões entre as formas de exploração do trabalho das mulheres dentro e fora de casa" (p. $31)$.

Raça e de gênero influenciarão as chances de um indivíduo se localizar em estado de pobreza e vulnerabilidade, razão pela qual considerar somente um desses fatores em uma análise traria um resultado incompleto sobre a realidade social. Gênero, raça e classe, atuando de maneira unida, provocam hierarquizações entre as mulheres, deixando as que são negras em situação pior (MIGUEL; BIROLI, 2015) ${ }^{13}$. Segundo Crenshaw (2002, p. 177), a interseccionalidade ${ }^{14}$

É uma conceituação do problema que busca capturar as consequências estruturais e dinâmicas da interação entre dois ou mais eixos da subordinação. Ela trata especificamente da forma pela qual o racismo, o patriarcalismo, a opressão de classe e outros sistemas discriminatórios criam desigualdades básicas que estruturam as posições relativas de mulheres, raças, etnias, classes e outras. Além disso, a interseccionalidade trata da forma como ações e políticas específicas geram opressões que fluem ao longo de tais eixos, constituindo aspectos dinâmicos ou ativos do desempoderamento [...] O racismo, por exemplo, é distinto do patriarcalismo, que por sua vez é diferente da opressão de classe. Na verdade, tais sistemas, frequentemente, se sobrepõem e se cruzam, criando intersecções complexas nas quais dois, três ou quatro eixos se entrecruzam.

Citando Crenshaw (2002), Biroli e Miguel (2015, p. 47) argumentam que o racismo, sexismo e dominações de classe "operam juntos e conjuntamente restringem ou potencializam

\footnotetext{
13 "Dados sócio-demográficos mostram que a posição social dos indivíduos é produzia pela combinação entre gênero, classe e raça" (BIROLI; MIGUEL, 2015, p. 51).

${ }^{14}$ Biroli e Miguel $(2015$, p. 47) destacam que as explicações de Crenshaw são importantes na medida em que trouxeram "o entendimento de que as formas de opressão não atingem os indivíduos isoladamente, mas também não o fazem somadas ou acopladas, em dinâmicas que permitiriam visualizar cada eixo de opressão [...]”. Além disso, outras feministas já faziam uma análise interseccional antes de Crenshaw, porém o termo foi por ela criado em sua tese de doutorado, em 1989 (RIBEIRO, 2018).
}

CONPEDI LAW REVIEW | EVENTO VIRTUAL | v. 6 | n. 1 | p. 19 - 35 | JAN - DEZ | 2020 
as trajetórias das pessoas. A noção de interseccionalidade permitiria compreender que os sistemas de dominação são múltiplos”. Collins (2015) alega ser importante pensar em raça, classe e gênero como categorias de análise, que permitem compreender uma estrutura marcada por dominação e subordinação. Para a autora, esses fatores "estruturam todas as relações" (p. 19).

Nesse contexto, Crenshaw (2002) ressalta as falhas de uma perspectiva que desconsidera todos esses fatores, o que gera movimentos de subinclusão e superinclusão. Este ocorre quando se tem unicamente uma perspectiva de gênero, sem considerar o racismo ou outra maneira de dominação naquele contexto. Gera-se, por consequência, um diagnóstico incompleto daquela realidade, refletindo na falta de efetividade dos atos de enfrentamento.

Paralelamente, a subinclusão ocorre "quando um subconjunto de mulheres subordinadas enfrenta um problema, em parte por serem mulheres, mas isso não é percebido como um problema de gênero, porque não faz parte da experiência das mulheres e dos grupos dominantes" (CRENSHAW, 2002, p. 175).

\begin{abstract}
Uma outra situação mais comum de subinclusão ocorre quando existem distinções de gênero entre homens e mulheres do mesmo grupo étnico ou racial. Com frequência, parece que, se uma condição ou problema é específico das mulheres do grupo étnico ou racial e, por sua natureza, é improvável que venha a atingir homens, sua identificação como problema de subordinação racial ou étnica fica comprometida. Nesse caso, a dimensão de gênero de um problema o torna visível enquanto uma questão de raça ou etnia. O contrário, no entanto, raramente acontece. Em geral, a discriminação racial que atinge mais diretamente os homens é percebida como parte da categoria de discriminações raciais, mesmo que as mulheres não sejam igualmente afetadas por ela (CRENSHAW, 2002, p. 175).
\end{abstract}

Cita como exemplo a esterilização de mulheres, em específico, porto-riquenhas e afro-americanas nos Estados Unidos ${ }^{15}$. Apesar de essas mulheres serem as vítimas principais dessa espécie de abuso quanto aos seus direitos reprodutivos, não é interpretada como decorrência de uma discriminação racial que ocorreu não somente nos anos de 1950, mas também em tempos mais próximos (CRENSHAW, 2002).

Aponta que no mundo inteiro a esterilização forçada de mulheres não é percebida como correlata a questões de raça (CRENSHAW, 2002). Contudo, "quando cuidadosamente examinada, se reconheçam aí 'fatores de risco', como raça, classe e outros, que determinam quais mulheres, mais provavelmente, sofrerão e quais não sofrerão esses abusos” (p. 175).

\footnotetext{
${ }^{15}$ Convém ressaltar que referido país já foi palco de outras políticas racistas, a exemplo das explicações de Davis (2016, p. 197) sobre a reivindicação pela maternidade voluntária.

CONPEDI LAW REVIEW | EVENTO VIRTUAL | v. 6 | n. 1 | p. 19 - 35 | JAN - DEZ | 2020 
Desse modo, “A interseccionalidade nos mostra como e quando mulheres negras são discriminadas e estão mais vezes posicionadas em avenidas identitárias, que farão delas vulneráveis à colisão das estruturas e fluxos modernos" (AKOTIRENE, 2019, p. 555). Assim, para que se garantam os direitos baseados no gênero para todas as mulheres ${ }^{16}$, é necessário "que se dê atenção às várias formas pelas quais o gênero intersecta-se com uma gama de outras identidades e ao modo pelo qual essas intersecções contribuem para a vulnerabilidade particular de diferentes grupos de mulheres" (CRENSHAW, 2002, p. 174).

Para Schwarcz (2019), compreender que a violência letal no país incide majoritariamente sobre uma parcela da população - que abrange as mulheres - e relacionar esse fato às desigualdades socioeconômicas que se relacionam a gênero, geração, região, é um movimento relevante para que se criem políticas públicas e ações afirmativas que objetivem diminuir essas desigualdades.

\begin{abstract}
As políticas públicas voltadas para o combate à violência doméstica, assim como para outras formas de violência de gênero, passam pela atuação do Estado [...]. E assim como partem de perspectivas que não reconhecem o racismo como uma realidade, negam também, ou se não negam ignoram, as intersecções entre esses marcadores. São as mulheres negras, ao exigirem dos movimentos negro e feminista o reconhecimento das especificidades que marcam as variadas formas de opressão que vivenciam, que impulsionam a construção de uma abordagem interseccional dos marcadores das diferenças e desigualdades (OLIVEIRA, 2016, p. 110).
\end{abstract}

Desse modo, uma visão interseccional contribui para que violências e desigualdades, que atingem determinados grupos de pessoas, sejam melhores compreendidas, pois se leva em conta as especificidades - como gênero, raça e classe - que influenciam na ocorrência desse cenário, permitindo-se uma compreensão da realidade que abarque diferentes sujeitos.

\title{
4 EMPODERAMENTO COMO MEIO DE TRANSFORMAÇÃO SOCIAL
}

Diante dos números alarmantes de violência, desigualdade e vulnerabilidades já apontados e compreendidos sob um viés intersecional, é interessante pensar em estratégias para alteração dessa realidade. Neste trabalho, relaciona-se o empoderamento como exemplo de instrumento de efetivação do direito às igualdades de gênero, raça e classe.

\footnotetext{
${ }^{16}$ Apesar de a expressão "mulheres" ser colocada no plural, aponta-se a impossibilidade de generalização como se pertencessem a uma categoria: Biroli e Miguel (2015, p. 39), com base em Hooks e Carneiro, destacam que "nessa crítica, aparecem como problema a unidade das mulheres e a generalidade da sua experiência, [...], mas também os mecanismos e relações de poder que produzem a ideia de que as mulheres negras correspondem a um grupo homogêneo".
} 
Scott (2018) destaca a relevância de ações transformam relações de gênero marcadas por hierarquias. Assim, deve-se levar em consideração, de forma indissociável, a relação entre patriarcado, classe e capitalismo existente na sociedade, para que os fenômenos sejam compreendidos, bem como ter em vista que são "formas de expressão dos antagonismos que envolvem a constituição patriarcal das relações de gênero que fazem parte das relações de classe e raça em um nó ${ }^{17}$ que constitui a estrutura social” (p. 92).

Depreende-se da obra de Collins (2015) que compreender as dificuldades da realidade do outro pode ser uma tarefa desafiadora: "Cada grupo identifica o tipo de opressão que se sente mais à vontade em atribuir como fundamental e classificam todos os outros tipos como menos importantes" (COLLINS, 2015, p. 13). Pensando em formas de se alcançar mudança social, aponta, dentre outras atitudes possíveis, a noção de empatia como sendo a capacidade de se interessar pelas experiências de grupos e de pessoas diferentes (COLLINS, 2015).

Berth (2019), citando as lições de Ribeiro, explica que para a autora, o conceito de empatia não se relaciona a um sentimento que surge inesperadamente, mas trata-se de uma construção que requer esforço, além de exigir a vontade de aprender e ouvir. O desenvolvimento da empatia aumenta na medida em que o indivíduo toma conhecimento de uma realidade marcada por opressão. Berth (2019) também ressalta que o processo de empoderamento de um grupo tende a ser desafiador, na medida em que alguns indivíduos, apesar de se conscientizarem sobre uma vertente de opressão, somente se interessam por aquilo que lhes afeta.

Citando hooks, Freire e Lorde, Berth (2019) ensina que a conscientização da opressão sem ação não tem grandes potencialidades, sendo necessária a conjugação de diversas frentes para que se compreendam de maneira mais abrangente as diferenças existentes entre os indivíduos. De fato, para Collins (2015, p. 15), "novas maneiras de pensar desacompanhadas de novas maneiras de agir oferecem possibilidades incompletas de mudanças". Tendo como base Freire, hooks, Colins, Davis e Batliwala, Berth (2019, p. 1299) conceitua empoderamento como "a aliança entre conscientizar-se criticamente e transformar na prática, algo contestador e revolucionário na sua essência”.

O empoderamento, assim como o lugar de fala, coloca-se em uma posição estratégica de descortinador da bipolaridade social, que ao mesmo tempo anseia pela

\footnotetext{
${ }^{17}$ Cita a expressão "nó" porque se refere ao que "é constituído pela relação estrutural existente entre patriarcadoracismo-capitalismo" (SAFFIOTI, 2004; apdu SCOTT, 2018, p. 92).

CONPEDI LAW REVIEW | EVENTO VIRTUAL | v. 6 | n. 1 | p. 19 - 35 | JAN - DEZ | 2020 
igualdade em um sintoma confuso de crise ética, mas não se mostra disposta a olhar para seus acúmulos e questioná-los no sentido de promover um recuo em nome de uma transformação social completa e possível (BERTH, 2019, p. 515).

Sardenberg (2012) esclarece que no Brasil não há um único entendimento sobre empoderamento. Além disso, Berth (2019) defende que não se trata de retirar poder de um indivíduo ou grupo para repassar a outro. Visualiza-o como um posicionamento que remete à luta voltada a extinguir cenários de injustiça e obtenção de igualdade social. Nesse sentido, Batliwala (1994, p. 130) ${ }^{18}$ o define como "o processo de desafiar as relações de poder existentes, e de obter maior controle sobre as fontes de poder".

É importante que não se tenha uma visão superficial dessa expressão, vez que não se resume à superação de determinadas opressões sem transgredir estruturas que oprimem (BERTH, 2019). Dessa forma, compreende-se empoderamento como o "conjunto de estratégias necessariamente antirracistas, antissexistas e anticapitalistas e as articulações políticas de dominação que essas condições representam” (p. 364). As ações conectadas à Teoria do Empoderamento devem visar mudanças sociais, violando as estruturas que condensam o poder que hierarquiza os indivíduos (BERTH, 2019).

\begin{abstract}
Empoderamento é a manifestado na redistribuição de poder, seja entre nações, classes, castas, raças, gêneros ou indivíduos. Os objetivos do empoderamento feminino são desafiar a ideologia patriarcal (dominação masculina e subordinação feminina); transformar as estruturas e instituições que reforçam e perpetuam discriminação de gênero e desigualdade social (a família, castas, classe, religião, processo educacional e instituições, a mídia, práticas de saúde e sistemas, leis e códigos civis, processos políticos, desenvolvimento de modelos, e instituições governamentais); e permitir às mulheres pobres a obtenção de acesso, e o controle, tanto de recursos materiais como informacionais (BATLIWALA, 1994, p. 130) ${ }^{19}$.
\end{abstract}

É possível identificar embates entre as ideias de empoderamento individual e coletivo. Aquele se relaciona à independência da assistência de outros para que se alcancem objetivos. No entanto, trata-se de uma visão que não considera questões sociais, ou seja, as formas de dominação, contexto sociopolítico, entre outros aspectos afins (LEÓN, 2001). Assim, "pode ser uma simples e mera ilusão, se não estiver conectado com o contexto e se

\footnotetext{
${ }^{18}$ Tradução das autoras. No original: "The process of challenging existing power relations, and of gaining greater control over the sources of power" (BATLIWALA, 1994, p. 130).

${ }_{19}$ Tradução das autoras. No original: "Empowerment is manifested as a redistribution of powers, whether between nations, classes, castes, races, genders, or individuals. The goals of woman's empowerment are to challenge patriarcal ideology (male domination and woman's subordination); to transform the structures and institutions that reinforce and perpetuate gender discrimination and social inequality (the family, caste, class, religion, educational process and institucions, the media, health practices and systems, laws and civil codes, political processes, development models, and government institutions); and to enable poor woman to gain acess to, and control of, both material and informational resources" (BATLIWALA, 1994, p. 130).
}

CONPEDI LAW REVIEW | EVENTO VIRTUAL | v. 6 | n. 1 | p. 19 - 35 | JAN - DEZ | 2020 
relacionar com ações coletivas dentro de um processo político" (p. 97) ${ }^{20}$. O empoderamento envolve mudanças a níveis individuais e coletivos (LEÓN, 2001):

O empoderamento como autoconfiança e autoestima deve se integrar em um sentido de processo com a comunidade, cooperação e solidariedade. Ao ter em conta o processo histórico que cria a ausência de poder, se deixa evidente a necessidade de alterar as estruturas sociais vigentes; ou seja, de reconhecer a necessidade de mudança (LEÓN, 2001, p. 97) ${ }^{21}$.

Essa teoria pode servir como meio de libertação e destruição de estruturas opressoras (BERTH, 2019). Além disso, Romano (2002) não admite neutralidade quanto à prática do empoderamento. Desvinculá-lo de questões políticas serviria somente para limitá-lo. O empoderamento se relaciona à noção de destruir relações de dominação que são fontes de desigualdades, presentes na sociedade de forma naturalizada, bem como nas instituições. Nesse sentido, busca por justiça e igualdade, e para tanto, deve-se escolher o lado dos que são pobres e oprimidos.

No entanto, o autor defende cautela para que não ocorra a superpolitização ou atomização (ROMANO, 2002). No primeiro caso, há "redução do empoderamento a um tipo de ação coletiva. Isto é, quando só dizem respeito ao trabalho de empoderamento as práticas e discursos políticos contestatórios, que tenham nas organizações ou movimentos seus autores quase exclusivos” (p. 13). Quanto ao segundo aspecto, o pesquisador esclarece que a teoria "vêm sofrendo a influência das tentativas de despolitização, fragmentação e atomização das situações de dominação, propiciadas pelo avanço do neoliberalismo, das teorias que vaticinam o fim das ideologias e da supervalorização da individualidade” (p. 13).

A fim de alcançar a mudança por meio do empoderamento, é interessante questionar como ocorre o processo de se empoderar. Segundo Batliwala (1994), para que se alterem relações de subordinação, é necessário que as mulheres percebam a dominação masculina que sobre elas recai, e que compreendam a influência sobre suas opressões. Diante disso, são necessárias alterações de valores, posturas e ideologias, na medida em que manipulam as mulheres desde que nasceram. Considerando a impossibilidade de se questionar, esse cenário foi internalizado como algo natural.

\footnotetext{
20 Tradução das autoras. No original: "Este empoderamiento puede ser una simple y mera ilusión, si no está conectado con el contexto y se relaciona con acciones colectivas dentro de un proceso político" (LEÓN, 2001, p. 97).

${ }^{21}$ Tradução das autoras. No original: "El empoderamiento como autoconfianza y autoestima debe integrarse en un sentido de processo con la comunidade, la cooperación y la solidariedad. Al tener en cuenta el processo histórico que crea la carencia de poder, se hace evidente la necessidad de alterar las estructuras sociales vigentes; es decir, de reconocer el imperativo del cambio" (LEÓN, 2001, p. 97).
}

CONPEDI LAW REVIEW | EVENTO VIRTUAL | v. 6 | n. 1 | p. 19 - 35 | JAN - DEZ | 2020 
Além disso, Batliwala (1994) sugere que as mulheres ajam em conjunto para que obtenham mudança. É imprescindível o reconhecimento dos problemas, criação de planos e ações, gerando, assim, consciência. Trata-se de um processo que afeta não somente os níveis individuais, mas também a coletividade, comunidade, dentre outros. Assim, as mulheres devem representar uma força política, questionando e alterando as relações desiguais de poder.

Segundo Berth (2019, p. 141), há “uma movimentação interna de tomada de consciência ou do despertar de diversas potencialidades que definirão estratégias de enfrentamento das práticas do sistema de dominação machista e racista". Segundo a autora, o empoderamento a níveis individual e coletivo caminham juntos (BERTH, 2019), pois "uma coletividade empoderada não pode ser formada por individualidades e subjetividades que não estejam conscientemente atuantes dentro de processos de empoderamento" (p. 389-401).

Examinando-o como um processo gradual, Berth (2019) aduz que embora um indivíduo pertencente a um grupo oprimido desenvolva pensamento crítico sobre sua situação, isso não é suficiente para a desconstrução das estruturas que o colocam numa situação de opressão. Para tanto, é necessário um empoderamento de toda a comunidade para que se libertem das violências que os atingem e se desliguem da fragilidade social. Assim, "seria preciso estabelecer a necessidade de avaliar e articular diversas dimensões de trabalho rumo à aplicação da Teoria do Empoderamento como instrumento de emancipação e erradicação das estruturas que oprimem" (p. 414).

Nesse sentido, Romano (2002, p. 18) entende o empoderamento como "um meio e um fim para a transformação das relações de poder existentes e para superar o estado de pobreza". Diante disso, verifica-se a importância do fortalecimento econômico dos grupos oprimidos (BERTH, 2019). Para a autora, “em uma realidade capitalista, é importante criar estratégias de fortalecimento econômico, e tal demanda é fundamental para surgimento de condições favoráveis ao empoderamento" (p. 1312).

Dessa maneira, o empoderamento é entendido como ferramenta que, por seu caráter de conscientização e enfrentamento às estruturas sociais opressoras, tende a contribuir para a garantia dos direitos fundamentais de indivíduos que sofrem constantes violações a partir da intersecção entre gênero, raça e classe.

\section{CONSIDERAÇÕES FINAIS}

CONPEDI LAW REVIEW | EVENTO VIRTUAL | v. 6 | n. 1 | p. 19 - 35 | JAN - DEZ | 2020 
Dados demonstram que a desigualdade que recai sobre mulheres negras é situação alarmante no Brasil, e diante disso, justificou-se o estudo do tema e a reflexão sobre formas de alteração dessa realidade. Assim, a pesquisa buscou responder: de que maneira o empoderamento feminino contribui para a efetivação dos direitos fundamentais das mulheres?

Para responder ao questionamento, partiu-se da hipótese - que se confirmou - de que o empoderamento - com seu caráter de transformação de estruturas sociais - permite a tomada de consciência das desigualdades a níveis individual e coletivo, e consequentemente, a criação de estratégias de enfrentamento.

Demonstrou-se a hipótese a partir de considerações sobre o racismo enfrentado por mulheres no Brasil, enfatizando-se dados sobre violência, desrespeito e desigualdade nas esferas laboral, educacional e em outros setores. Foi elementar, nesse sentido, o feminismo negro e o movimento negro, na medida em que trouxeram voz às demandas.

Além disso, defendeu-se que uma análise interseccional é a mais adequada para a compreensão da realidade, realçando-se que uma análise pautada em somente um desses fatores gera um diagnóstico incompleto do cenário desigual, e consequentemente, ações sem a efetividade necessária.

Por fim, pensou-se o empoderamento, especialmente a partir das lições de Berth (2019), Batliwala (1994), Romano (2002) e León (2001), como forma de se alcançar mudança de estruturas sociais. Assim, trata-se de um instrumento de enfrentamento às opressões, por meio de conscientização do poder, união e criação de estratégias de cunho transformador.

\section{REFERÊNCIAS}

AKOTIRENE, Carla. Interseccionalidade. São Paulo: Sueli Carneiro; Pólen, 2019. [Recurso Eletrônico].

ALMEIDA, Silvio Luiz de. O que é racismo estrutural? Belo Horizonte: Letramento, 2018.

BERTH, Joice. Empoderamento. São Paulo: Sueli Carneiro; Pólen, 2019. [Recurso Eletrônico].

BATLIWALA, Srilatha. The Meaning of Woman's Empowerment: New Concepts from Action. In: SEM, Gita; GERMAIN, Adrienne; CHEN, C. (Editors). Population policies reconsidered: health, empowerment, and rights. Boston, Massachussets: Harvard School of Public Heallth, 1994. p. 127-173

BERTÚLIO, Dora Lucia de Lima. Direito e relações raciais: uma introdução crítica ao racismo. Dissertação (Mestrado em Ciências Humanas - Especialidade Direito) - Curso de Pós-Graduação em Direito, Universidade Federal de Santa Catarina, Florianópolis, 1989. 
BIROLI, Flávia; MIGUEL, Luis Felipe. Gênero, raça e classe: opressões cruzadas e convergências na reprodução das desigualdades. Mediações - Revista de Ciências Sociais, Londrina, v. 20, n. 2, p. 27-55, jul/dez. 2015. ISSN: 2176-6665. Disponível em: http://www.uel.br/revistas/uel/index.php/mediacoes/article/view/24124. Acesso em: 31 jul. 2019. Doi: http://dx.doi.org/10.5433/2176-6665.2015v20n2p27.

CARNEIRO, Sueli. Mulheres em movimento. Estud. av., São Paulo, v. 17, n. 49, p. 117-133, dez. 2003. Disponível em: http://www.scielo.br/scielo.php?script=sci_arttext\&pid=S010340142003000300008\&lng=en\&nrm=iso. Acesso em: 31 jul. 2020.

Doi: http://dx.doi.org/10.1590/S0103-40142003000300008.

COLLINS, Patricia Hills. Em direção a uma nova visão: raça, classe e gênero como categorias de análise e conexão. In: MORENO, Renata (Org.). Reflexões e práticas de transformação feminista (Coleção Cadernos Sempreviva. Série Economia e Feminismo, 4). São Paulo: SOF, 2015, p. 13-96. Disponível em: http://www.sof.org.br/wpcontent/uploads/2016/01/reflex\%C3\%B5esepraticasdetransforma\%C3\%A7\%C3\%A3ofeminis ta.pdf. Acesso em: 31 jul. 2020.

CRENSHAW, Kimberlé. Documento para o encontro de especialistas em aspectos da discriminação racial relativos ao gênero. Revista Estudos Feministas, Florianópolis, v. 10, n. 1, p. 171-188. 2002. ISSN: 0104-026X. Disponível em: http://www.scielo.br/scielo.php?pid=S0104026X2002000100011\&script=sci_abstract\&tlng=pt. Acesso em: 31 jul. 2020. Doi: http://dx.doi.org/10.1590/S0104-026X2002000100011.

DAVIS, Angela. Mulheres, raça e classe. Tradução: Heci Regina Candiani. São Paulo: Boitempo, 2016.

INSTITUTO DE PESQUISA ECONOMICA APLICADA; FÓRUM BRASILEIRO DE SEGURANÇA PÚBLICA. Atlas da Violência 2019. Brasília: Rio de Janeiro: São Paulo. 2019. Disponível em: http://www.ipea.gov.br/portal/index.php?option=com_content\&view=article\&id=34784\&Ite mid=432. Acesso em: 31 jul. 2020.

LEÓN, Magdalena. El empoderamiento de las mujeres: Encuentro del primer y tercer mundos em los estúdios de género. La Ventana, [S. I.], v. 2, n. 13, p. 94-106, 2001. ISSN: 1405-9436. Disponível em: https://dialnet.unirioja.es/servlet/articulo?codigo=5202169. Acesso em: 31 jul. 2020.

LIMA, Francielle Elisabet Nogueira. Perspectivas críticas sobre a tutela jurídica de pessoas trans: diálogos entre estudos (trans)feministas e direito. Dissertação (Mestrado em Direito) Programa de Pós-Graduação em Direito, Universidade Federal do Paraná, Curitiba, 2018.

OLIVEIRA, Tatyane Guimarães. Qual a classe, a cor e o gênero da justiça? Reflexões sobre as (im)possibilidades de combate à violência doméstica e familiar contra as mulheres negras pelo Poder Judiciário brasileiro. Mediações - Revista de Ciências Sociais, Londrina, v. 21, n. 1, p. 103-123, jul/dez. 2016. ISSN: 2176-6665. Disponível em: 
http://www.uel.br/revistas/uel/index.php/mediacoes/article/view/24677. Acesso em: 31 jul. 2020. Doi: 10.5433/2176-6665.2016v21n1p103.

REDAÇÃO. Trabalho doméstico: mulheres negras são a maioria na categoria e têm os piores salários, Nós, mulheres na periferia, não paginado, 8 mar. 2015. Disponível em:

http://nosmulheresdaperiferia.com.br/noticias/trabalho-domestico-mulheres-negras-sao-amaioria-na-categoria-e-tem-os-piores-salarios/. Acesso em: 31 jul. 2020.

RIBEIRO, Djamila. O que é: lugar de fala? Belo Horizonte (MG): Letramento: Justificando, 2017.

RIBEIRO, Djamila. Quem tem medo do feminismo negro? São Paulo: Companhia das Letras, 2018. [Recurso Eletrônico].

ROMANO, Jorge O. Empoderamento: recuperando a questão do poder no combate à pobreza. In: ROMANO, Jorge O.; ANTUNES, Marta (Org.). Empoderamento e direitos no combate à pobreza. Rio de Janeiro: ActionAid Brasil, 2002. p. 9-20.

SARDENBERG, Cecília M. B. Conceituando "Empoderamento" na perspectiva feminista. 2012. Disponível em: https://repositorio.ufba.br/ri/handle/ri/6848. Acesso em: 31 jul. 2020. [Transcrição revisada da comunicação oral apresentada ao I Seminário Internacional: Trilhas do Empoderamento de Mulheres - Projeto Tempo, promovido pelo NEIM/UFBA, em Salvador, Bahia, de 5-10 de junho de 2006].

SCHWARCZ, Lilia Moritz. Sobre o autoritarismo brasileiro. São Paulo: Companhia das Letras, 2019.

SCOTT, Juliano Beck. Grupos reflexivos com homens autores de violência doméstica contra a mulher: limites e potencialidades. Tese (Doutorado em Psicologia) - Programa de PósGraduação em Psicologia, Universidade Federal do Rio Grande do Norte, Natal, 2018. Disponível em: https://repositorio.ufrn.br/jspui/handle/123456789/26621. Acesso em: 31 jul. 2020.

SUDRÉ, Lu. Preta Rara: “A senzala moderna é o quartinho da empregada”, lançado recentemente, livro "Eu, empregada doméstica" reúne relatos de violências vividas por trabalhadoras em todo país, Brasil de Fato, uma visão popular do Brasil e do mundo, São Paulo, não paginado, 8 out. 2019. Disponível em:

https://www.brasildefato.com.br/2019/10/08/preta-rara-a-senzala-moderna-e-o-quartinho-daempregada/. Acesso em: 31 jul. 2020.

TIBURI, Marcia. Feminismo em comum: para todas, todes e todos. Rio de Janeiro: Rosa dos Tempos, 2018. [Recurso eletrônico].

WAISELFISZ, Julio Jacobo. Mapa da Violência 2015: Homicídio de Mulheres no Brasil. Brasília: Flacso Brasil, 2015. Disponível em: http://www.onumulheres.org.br/wpcontent/uploads/2016/04/MapaViolencia_2015_mulheres.pdf. Acesso em: 31 jul. 2020. 